\title{
Clinical and Molecular Update on Genetic Causes of Pituitary Adenomas
}

\author{
Authors \\ Vladimir Vasilev ${ }^{1,2}$, Adrian F. Daly ${ }^{1}$ (D), Sabina Zacharieva², Albert Beckers ${ }^{1}$
}

\author{
Affiliations \\ 1 Department of Endocrinology, CHU de Liège, Liège \\ Université, Liège, Belgium \\ 2 Department of Endocrinology, Medical University, Sofia, \\ Bulgaria
}

Key words

pituitary adenoma, GNAS, AIP, USP8, MEN1, GPR101, Carney complex, X-LAG, FIPA

$\begin{array}{ll}\text { received } & 14.08 .2019 \\ \text { accepted } & 11.03 .2020\end{array}$

Bibliography

DOI https://doi.org/10.1055/a-1143-5930

Published online: 16.4.2020

Horm Metab Res 2020; 52: 553-561

(c) Georg Thieme Verlag KG Stuttgart · New York

ISSN 0018-5043

Correspondence

Prof. Albert Beckers MD, PhD

Department of Endocrinology, CHU de Liège, Liège

Université, Domaine Universitaire du Sart-Tilman

4000 Liège

Belgium

albert.beckers@chu.ulg.ac.be

\begin{abstract}
Pituitary adenomas are benign tumors with variable functional characteristics that can have a significant impact on patients. The majority arise sporadically, but an inherited genetic susceptibility is increasingly being recognized. Recent advances in genetics have widened the scope of our understanding of pituitary tumorigenesis. The clinical and genetic characteristics of pituitary adenomas that develop in the setting of germlinemosaic and somatic GNAS mutations (McCune-Albright syndrome and sporadic acromegaly), germline MEN1 mutations (multiple endocrine neoplasia type 1), and germline PRKAR1A mutations (Carney complex) have been well described. Non-syndromic familial cases of isolated pituitary tumors can occur as familial isolated pituitary adenomas (FIPA); mutations/deletions of the AIP gene have been found in a minority of these. Genetic alterations in GPR101 have been identified recently as causing X-linked acro-gigantism (X-LAG) leading to very early-onset pediatric gigantism. Associations of pituitary adenomas with other tumors have been described in syndromes like multiple endocrine neoplasia type 4, pheochromocytoma-paraganglioma with pituitary adenoma association (3PAs) syndrome and some of their genetic causes have been elucidated. The genetic etiologies of a significant proportions of sporadic corticotropinomas have recently been identified with the discovery of USP8 and USP48 mutations. The elucidation of genetic and molecular pathophysiology in pituitary adenomas is a key factor for better patient management and effective follow-up.
\end{abstract}

\section{Introduction}

Pituitary tumors develop as a result of the abnormal proliferation of anterior pituitary cells into adenomas. They are almost always benign and are the second most common intracranial neoplasm following meningiomas according to large cancer registries [1]. Their prevalence in the general population has been estimated from historical autopsy studies and radiological series to be around $15-22 \%$ [2]. The increased use and accessibility of imaging techniques as well as improved spatial resolution of modern devices has led to a rise in incidental detection of pituitary adenomas. The vast majority of these incidentalomas are hormonally inactive microadenomas with no clinical significance. The real challenge for medical specialists, however, are clinically relevant pituitary adenomas - namely those that lead to symptoms of hormonal overexpression and/or compression of adjacent structures. Following initial data from Liège, Belgium in 2006 showing a rate of 1 case of clinically-relevant pituitary adenomas per 1064 of the general population, several subsequent cross-sectional studies have confirmed these data [3-6].

Despite their prevalence, the exact pathophysiological mechanisms that lead to pituitary adenoma predisposition and formation are still not fully elucidated. Tumorigenesis classically involves activation of oncogenes or inactivation of tumor suppressor genes or both. Pituitary adenomas are thought to be monoclonal and to arise from a single mutated cell [7]. The majority of pituitary adenomas are sporadic and around $5 \%$ of them arise in a familial fashion [8]. Familial forms of diseases, however, have always presented opportunities for researchers to elucidate the underlying genetic factors as they provide basis for identifying, mapping and characterization of relevant genes. Well established genetic causes of 
pituitary adenomas include mutations in GNAS in sporadic acromegaly (somatic) and McCune-Albright syndrome (mosaic germline) as well as mutations predisposing to classical multiple neoplasia syndromes like MEN1 and Carney complex. The definition of familial isolated pituitary adenomas (FIPA) was followed by the identification of mutations in the AIP gene in up to a quarter of FIPA kindreds. Intensive genetic research in the last decade has led to the identification of a number of new genetic alterations that lead to either sporadic or familial development of pituitary adenomas. Quite recently duplications in GPR101 gene have been linked to early-onset gigantism that was termed X-LAG. Mutations in USP8/USP48 and CABLES1 genes have been associated with sporadic Cushing's disease. Predisposition to pituitary adenomas also exists in other syndromes, such as, multiple endocrine neoplasia type 4 (MEN4), pheochormocytoma-paraganglioma with pituitary adenoma syndrome (3PAs), DICER1 syndrome, tuberous sclerosis complex (TSC) and neurofibromatosis type 1 (NF1).

\section{GNAS and McCune Albright Syndrome}

Secretion of many of anterior pituitary hormones is regulated through the G-protein coupled signal transduction pathways. The GNAS gene encodes the stimulatory alpha subunit of a heterotrimeric G-protein (Gs $\alpha$ ). Gain-of-function mutations in GNAS at two specific sites, predominantly at codon 201 and less often at codon 227, result in loss of GTP-ase activity and permanent activation of adenylyl cyclase [9]. The consequent increase in cAMP stimulates the protein kinase $A(P K A)$ pathway and leads to hormone hypersecretion and cell proliferation. Somatic mutations in GNAS gene, also called the gsp oncogene, have been identified in up to $40 \%$ of sporadic acromegaly cases [10], around $10 \%$ in non-functioning pituitary adenomas (NFPA) [11] and in several cases of corticotropinoma [12]. Some studies suggest that acromegalic patients with gsp mutant pituitary adenomas respond better to first-generation somatostatin analog treatment $[13,14]$. The clinical relevance of gsp mutations in NFPA and the exact pathophysiological mechanisms in NFPA remain to be elucidated.

When mutations in GNAS happen early in embryonic development, mutant cells are mosaically distributed through different organs, which leads to McCune-Albright syndrome (MAS). This is a very rare sporadic disorder that classically was described as a triad of polyostotic fibrous dysplasia (FD), café-au-lait skin pigmentation and peripheral precocious puberty [15]. In addition, many other tissues can be affected including pituitary, adrenals, thyroid, parathyroid and pancreas as well as non-endocrine organs like liver and thymus $[16,17]$. The clinical presentation varies widely depending on the degree of mosaicism and the expression of the mutant allele in the tissues. Parental genetic imprinting also accounts for disease heterogeneity as only the maternal allele is expressed in pituitary, thyroid and ovaries [18]. Acromegaly or gigantism usually accompanied by hyperprolactinemia can be present in about $20 \%$ of patients with MAS [17]. Unlike sporadic cases, however, MRI fails to identify a pituitary adenoma in the majority of cases and $\mathrm{GH}$ excess is frequently due to pituitary hyperplasia [16]. MAS patients should always undergo laboratory screening for $\mathrm{GH}$ excess. Treatment of MAS patients with gigantism or acromegaly also presents a challenge. Skull base FD and obliteration of sphenoid sinus can make a trans-sphenoidal surgical approach very difficult. The lack of identifiable adenoma on MRI additionally limits the use of surgery. Radiotherapy may also be unacceptable because of the young age of the patients and the increased possibility for malignant transformation of irradiated FD [19]. With this in mind, medical therapy is an important practical option for managing $\mathrm{GH}$ excess in MAS. Long-acting somatostatin analogs and $\mathrm{GH}$ receptor antagonists alone or in combination have been shown to be effective $[20,21]$. Dopamine agonist can be used for managing accompanying hyperprolactinemia.

\section{USP8}

Until recently ACTH-secreting pituitary adenomas causing Cushing's disease were only rarely associated with the known genetic mutations in sporadic and familial pituitary tumors. In 2015, however, a novel mutational hotspot was identified by next generation sequencing in exon 14 of the ubiquitin specific peptidase 8 (USP8) gene on chromosome 15q21.1 [22]. USP8 functions as deubiquitinase of tyrosine kinase receptors, particularly epithelial growth factor receptor (EGFR), and prevents ubiquinated receptors from undergoing lysosomal degradation [23]. All identified mutations affect a highly conserved region of the gene which codes an amino acid sequence crucial for the regulation of enzyme activity. It serves as a binding site for $14-3-3$ proteins which inhibit USP8 function [24]. The loss of protective 14-3-3 binding allows for proteolytic cleavage of a C-terminal $40 \mathrm{kD}$ protein fragment with increased and unrestricted deubiquitinase activity [22]. This, in turn, leads to continuous EGFR recycling and constantly activated downstream signaling. In corticotrope cells expression of POMC is induced by EGFR through Erk1/Erk2 and increased stimulation of the receptor leads to ACTH overproduction and cell proliferation [25]. To date, heterozygous single point mutations in USP8 have been identified in up to $60 \%$ of adult and $30 \%$ of pediatric patients with CD [25, 26]. All cohorts show that mutations are more frequently detected in females but other associations with the mutational status are not consistent throughout different studies. It has been shown that USP8-mutated corticotropinoma cell express more type 5 somatostatin receptors [27] and it might be that these tumors could respond better to pasireotide therapy. The elucidation of the role of the EGFR pathway in the etiology of CD presents opportunities for new targeted therapies, such as, tyrosine kinase inhibitors like gefitinib - an oral EGFR inhibitor, currently approved for metastatic non-small cell lung carcinoma.

Previously reported USP8 mutations leading to Cushing's disease are generally somatic but recently a de novo germline mutation was described [28]. Apart from recurrent corticotropinoma the affected patient with a complex syndrome of development delay, dysmorphic features, ichtyosiform hyperkeratosis, chronic lung and kidney disease, cardiomyopathy, hyperinsulinemia and partial growth hormone deficiency. At least some of these disorders could be attributed to the disrupted EGFR pathway in other tissues.

\section{CABLES1}

Another genetic alteration that may be potentially involved in corticotropinoma development was recently identified in CDK5 and 
ABL1 enzyme substrate 1 (CABLES1) gene located on chromosome $18 q 11.2$ [29]. It is a glucocorticoid responsive negative cell-cycle regulator and plays a role in maintaining the normal negative adrenal-pituitary feedback loop [30]. The loss of CABLES1 expression in corticotrope cell lines results in an increase of proliferation probably through destabilization of p21 $1^{\text {Cip } 1}$ and down regulation of p27 Kip1. Loss-of-function missense mutations in CABLES1 were detected in four female patients out of a cohort of 181 patients with CD (2.2\%) [29]. All affected patients presented with young-onset pituitary macroadenoma with high proliferation index and aggressive behavior.

\section{Familial Pituitary Adenomas}

MEN1

Multiple endocrine neoplasia type 1 (MEN1) is a rare autosomal dominant syndrome with high penetrance and no sex predominance. It is characterized by the combined occurrence of primary hyperparathyroidism, enteropancreatic neuroendocrine tumors and pituitary adenomas. Apart from these three main types of neoplasms, over 20 other endocrine and non-endocrine tumors have been described in association with MEN1. These include carcinoid tumors and adrenal cortical tumors, usually non-secreting, as well as various inactive benign lesions such as lipomas, facial angiofibromas, meningiomas and collagenomas [31]. MEN1 is caused by mutations or deletions of the MEN1 gene on chromosome 11q13 $[32,33]$ that encodes the protein menin. MEN1 is a tumor suppressor gene and its transcript has been shown to interact with a variety of proteins that take part in transcriptional regulation, genome stability, cell proliferation and apoptosis. Localized predominantly in the nucleus, menin suppresses Jun-D and NF-kB-mediated transcriptional activation, participates in the regulation of transforming growth factor- $\beta$ (TGF- $\beta$ ) signaling pathways by interacting with Smad family of proteins, regulates the expression of cyclin-dependent kinase inhibitors genes $\mathrm{p} 27$ and $\mathrm{p} 18$ by being a component in histone methyltransferase complexes, inhibits cell proliferation through interacting with the activator of S-phase kinase and maintains stable gene expression by controlling genome stability and DNA replication and repair [34]. However, none of the numerous menin functions has yet been proven critical in MEN1 tumorigenesis. So far over 1800 mutations in MEN1 gene have been identified and they are spread throughout the whole coding sequence and include $41 \%$ frameshift deletions, $23 \%$ nonsense mutations, $20 \%$ missense mutations, $9 \%$ splice-site mutations, $6 \%$ in-frame deletions and $1 \%$ whole gene deletions [35]. The majority of these mutations lead to loss of menin function.

Sporadic and familial forms of MEN1 have been described with the latter being much more frequent $(90 \%)$. The first organ to manifest tumorigenesis in MEN1 is usually the parathyroid and it has a penetrance of $95 \%$ at the age of 50 [36]. Diagnosed in 35-80\% of patients, pancreatic islet cell tumors are the second most common presentation of MEN1 and are mostly characterized by excessive hormone production leading to marked clinical symptoms. Gastrinomas causing Zollinger-Ellison syndrome account for nearly a half of pancreatic lesions in MEN1 and due to multiple peptic ulcers and a large proportion of malignant tumors they represent one of the major causes for mortality and morbidity in this condition [37].
The prevalence of pituitary tumors in MEN1 varies widely from $10-72 \%$ in different studies and they are the first clinical manifestation of the disease in up to $25 \%$ of patients [38]. However, only $2.7 \%$ of all pituitary adenomas can be attributed to MEN1 [39]. Pituitary pathology is much more prevalent in familial MEN1 cases compared to non-familial ones. Also, women with MEN1 have an increased predisposition to having a pituitary adenoma. Nearly all types of pituitary tumors have been reported, with prolactinomas being the most frequent, but the general proportions of prolactin-secreting, $\mathrm{GH}$-secreting, ACTH-secreting and non-functional adenomas remain similar in MEN1 cases and sporadic populations [40]. Pituitary tumors in MEN1, however, appear to be larger and more aggressive than their sporadic counterparts and macroadenomas comprise approximately $85 \%$ of them compared to only $42 \%$ of non-MEN1 pituitary adenomas. This tendency for aggressiveness is especially well observed in MEN1 prolactinomas where the proportion of macroadenomas reaches $84 \%$ in contrast to the general population where microadenomas are the predominant prolactinoma phenotype [8]. So far no evident genotype-phenotype correlations have been observed although historically some kindreds with prolactinomas were reported in Canada, Tasmania, and Brazil [38].

\section{Carney Complex}

Carney complex (CNC) is another autosomal dominant disorder that may be associated with pituitary pathology. It presents with spotty dermatological and mucosal pigmentation, myxomas of the heart and other tissues, schwannomas and various endocrine and non-endocrine tumors [41]. CNC is genetically heterogeneous. Around $70 \%$ of all cases are caused by inactivating mutations in the gene for type $1 \mathrm{~A}$ regulatory subunit of protein kinase $\mathrm{A}$ (PRKAR1A), located on chromosome 17q22-24 [42]. Protein kinase $A(P K A)$ is a cAMP-dependent protein kinase composed of two regulatory and two catalytic subunits and is a component of a wide range of metabolic and regulatory pathways involved in cell proliferation, transcription and apoptosis. Over 140 mutations in PRKAR1A have been identified and approximately $80 \%$ them lead to premature stop codon generation, subsequent degradation of nonsense mRNA and resultant PRKAR1A haploinsufficency [41]. The loss of type $1 \mathrm{~A}$ regulatory subunits disrupts the balance in PKA tetramer formation and induces release of free catalytic subunits resulting in increased cAMP-dependent kinase activity in affected tissues [43]. Another potential CNC related locus on chromosome 2p16 was previously reported [44]; more recently, amplification of the gene for the catalytic beta subunit of PKA (PRKACB) was reported in a single patient with clinical presentation of CNC [45].

Approximately $70 \%$ of cases with CNC present in a familial fashion with female predominance [41]. Benign skin lesions are the most common clinical manifestation of the disease and include lentiginosis, cutaneous or mucosal myxomas, blue nevi and café-aulait spots. Cardiac myxomas are the most frequent non-cutaneous lesions in CNC and account for more than a half of the disease-specific mortality. Endocrine abnormalities are observed in approximately a third of CNC patients and are mainly due to Cushing's syndrome caused by primary pigmented nodular adrenocortical disease (PPNAD). Less common endocrine presentations include large 
cell calcifying Sertoli cell tumors (LCCSCTs) and benign or malignant thyroid nodules [46]. Pituitary adenomas develop in 10-12\% of CNC patients and usually cause acromegaly or gigantism depending on the age of onset. Prolactinomas have also been reported rarely [47]. However, $75 \%$ of patients can have elevations of $\mathrm{GH}$ and IGF-1 without detectable pituitary adenoma. A distinguishing feature of acromegaly in CNC is multifocal hyperplasia of somatomammotrope cells amidst normal pituitary tissue that may precede the formation of pituitary adenoma [41]. In such cases medical therapy may be the preferable treatment option since curative surgery would require partial or total hypophysectomy. Although Cushing's syndrome in CNC is usually of adrenal origin due to PPNAD, at least two cases of pituitary corticotropinomas have been described [48]. Some genotype-phenotype correlations may be present in CNC. Patients with large deletions in PRKAR1A may present with more severe disease while mutations in exons are more often associated with acromegaly, myxomas, lentigines, and shwannomas $[41,48]$. CNC patients with mutated PRKAR1A may present with skin pigmentation, myxomas, schwannomas, thyroid tumors and LCCSCTs more frequently and at younger age than CNC patients without an identified PRKAR1A mutation [49].

\section{MEN4}

Despite the large number of alterations found in MEN1 gene, genetic investigations still fail to identify mutations in $10-20 \%$ of patients who meet the clinical diagnostic criteria for MEN1 syndrome. Pathogenic alterations in the cyclin dependent kinase inhibitor $1 b$ gene (CDKN1B) were initially detected in rats with MEN1-like features (MENX) and the subsequent identifications of such mutations in humans with MEN1 phenotype led to the definition of a novel syndrome - multiple endocrine neoplasia type 4 (MEN4) [50]. CDKN1B is located on chromosome 12p13.1 and encodes the p27 Kip1 protein that belongs to the cyclin dependent kinase (CDK) inhibitor family that regulate cell cycle progression and arrest. p27 mainly inhibits cyclin E/CDK2 complex and is regulated, in turn, by proteosomal degradation through the mitogen activated kinase (MAPK) and phosphatidyl inositol 3 kinase (PI3K) pathways. Expression of p27 is also regulated by menin suggesting that mechanisms of tumorogenesis of MEN1 and 4 may be interconnected [51]. To date, 42 cases with 17 different mutations have been reported, the majority of them being missense, but also frameshift and nonsense mutations [48, 52]. They generally lead to faster p27 degradation, reduced binding to interacting partners and decreased nuclear translocation of p27 [51]. MEN4 may present sporadically or it can be inherited in an autosomal dominant fashion. Almost all reported patients develop primary hyperparathyroidism but at a later age as compared with MEN1 patients [53]. Pituitary adenomas are the second most frequent presentation of MEN4 and include non-functioning adenomas, somatotropinomas, prolactinomas, and corticotropinomas. Other less common manifestations include gastrointestinal neuroendocrine tumors as well as bilateral benign adrenal adenomas [51]. Overall, mutations in CDKN1B gene may explain MEN1-like phenotypes in less than $3 \%$ of cases that are negative for MEN1 mutations [54] and due to the rarity of the disease no genotype-phenotype correlations have been established so far.

\section{Familial Isolated Pituitary Adenomas}

Familial isolated pituitary adenomas (FIPA) describes the presence of pituitary adenomas of any type in at least two related members of the same kindred in the absence of clinical and genetic evidence of other known syndromic diseases [55, 56].It is inherited in an autosomal dominant pattern with low or variable penetrance. Depending on the tumor phenotype in the individual families, FIPA can be divided into a homogeneous type when all affected members have the same type of adenoma, and heterogeneous - with different secreting/non-secreting types of pituitary tumors within one family. Prolactinomas are the most common (37.5\%) and are usually microadenomas as is the case in non-familial pituitary tumors [57]. When they occur in heterogeneous FIPA families, however, they exhibit more aggressive behavior with significantly higher rates of suprasellar expansion and cavernous sinus invasion than sporadic prolactinomas. Somatotropinomas are the second most frequent secretory phenotype in FIPA (35\%) - much higher than in the general epidemiological population of pituitary adenoma patients. They are equally distributed between homogeneous and heterogeneous families but are more aggressive when occurring in a homogeneous setting. In homogeneous FIPA, acromegaly can be diagnosed 10 years earlier with tumors more frequently displaying extrasellar growth compared to heterogeneous kindreds and sporadic populations [57]. Non-functioning pituitary adenomas (NFPA) account for $14.5 \%$ of FIPA patients and predominantly occur in heterogeneous families. They experience more aggressive characteristics than sporadic counterparts and have earlier age of onset and a more invasive evolution [57]. Corticotropinomas (2.9\%), gonadotropinomas ( $1.9 \%)$, and thyrotropinomas ( $0.5 \%$ ) are quite rare and are usually associated with other adenoma types in heterogeneous families. Overall, FIPA accounts for approximately $2 \%$ of clinically relevant pituitary tumors [55], reaching up to $4 \%$ when considering only functioning PA [58].

Inactivating mutations in the gene for aryl-hydrocarbon receptor interacting protein (AIP) on chromosome 11q13.2 have been identified as a cause of FIPA [59]. To date, over 100 different mutations in AIP have been found and they are considered responsible for development of pituitary tumors in around $20 \%$ of FIPA kindreds $[48,60,61]$. Genetic alterations of AIP are detected also in approximately $4 \%$ of sporadic pituitary adenomas and up to $20 \%$ in young patients with sporadic macroadenomas $[62,63]$. The AIP gene is universally expressed in various tissues throughout the body and in normal pituitary it is associated with secretory granules in somatotrope and lactotrope cells. AIP encodes a 330 amino acid protein whose sequence is highly conserved across species [64]. The transcript houses an $\mathrm{N}$-terminal immunophilin like domain and a C-terminal end with three tetratricopeptide repeat (TPR) domains and a final $\alpha$-helix which are responsible for binding to the numerous interacting partners of AIP. Probably the best characterized partner is the aryl hydrocarbon receptor (AhR) - a ligand inducible transcription factor that modulates cellular responses to various xenobiotic toxins, such as dioxins, as well as some endogenous compounds like CAMP. In the absence of ligands AhR binds to two molecules of the $90 \mathrm{kDa}$ heat shock protein (hsp90) with AIP and p23 proteins, acting as co-chaperones, to form a multiprotein complex in the cytoplasm. The activation of the complex by its 
xenobiotic ligand results in nuclear translocation where AhR binds to the aryl hydrocarbon receptor nuclear translocator (ARNT) and promotes the transcription of specific genes coding various drug metabolizing enzymes as well as other proteins such as the cyclin dependent kinase inhibitor p21 [65]. AhR has been shown to act as a tumor suppressor gene in the pituitary and AIP could potentially maintain its stability by protecting it from ubiquitin dependent degradation [66]. Another pathophysiological link between AIP and pituitary tumorigenesis may lie in the interaction with the PKA pathway. AIP interacts with the inhibitory $G$ protein $G_{\alpha 1}$ and loss of AIP may be associated with reduced inhibitory $G$ protein function [67]. By directly or indirectly influencing specific phosphodiesterases like PDE4A5, AIP may participate in regulating cellular CAMP levels and PKA activity [68]. Moreover, binding to PDE2A interrupts the nuclear translocation of the AhR complex possibly by local reduction in CAMP levels [57]. Quite recently, it has been demonstrated that AIP physically interacts with both the catalytic (PRKACA) and the regulatory (PRKAR1A) subunits of PKA [69]. Other interacting partners of AIP include the tyrosine kinase receptor, encoded by the RET protooncogene, a number of nuclear receptors including the peroxisome proliferator-activated receptor $\alpha$ (PPAR $\alpha$ ), the glucocorticoid receptor, thyroid hormone receptor $\beta 1$, cytoskeleton proteins such as TUBB and TUBB2A [57, 70]. Despite the large number of identified partners and molecular pathways, however, the exact mechanisms of AIP induced tumorigenesis are still not known.

All types of pituitary tumors may occur in association with AIP mutations but $\mathrm{GH}$-secreting adenomas predominate occurring in about $70 \%$ of patients [71]. They are associated with much earlier age of onset, larger adenoma size and higher hormonal activity at diagnosis than non-AIP related acromegaly. Invasive macroadenomas occur in childhood or adolescence in more than half of the patients with AIP mutations and almost a third of AIP mutated somatotropinomas present with gigantism [60]. Somatostatin analogues are less effective for lowering GH and IGF-1 levels and inducing tumor shrinkage in somatotropinomas due to AIP mutations. These patients have significantly worse long-term therapeutic control and they frequently need multiple surgeries and radiotherapy. Prolactinomas due to AIP mutations also present with larger size, invasive features and are more often resistant to dopamine agonists [60]. Mutations that effect the C-terminal end of AIP and lead to truncated protein are usually associated with significantly lower age at diagnosis, indicating a possible genotype-phenotype correlation [61].

\section{X-LAG Syndrome}

Studies on series of patients with pituitary gigantism have recently identified a new genetic cause for $\mathrm{GH}$-secreting pituitary adenomas. The condition was named X-linked acrogigantism (X-LAG) as the underlying genetic alterations are due to microduplications of chromosome Xq26.3 [72, 73]. X-LAG develops in very early childhood. It is the second most common genetic cause $(10 \%)$ in the general cohort of patients with pituitary gigantism after AIP mutations (29\%) [63]. The duplicated genomic region includes GPR101, which is highly overexpressed in pituitary tumors of X-LAG patients. Its pathogenic role was further supported by the identification of a patient with duplication affecting only GPR101 gene [74]. The genetic product is an orphan G-protein coupled receptor [75]. The receptor is expressed in fetal pituitary and has been suggested to play a role in early pituitary development. In adults GPR101 is expressed mostly in the nucleus accumbens. Elevated levels of $\mathrm{GH}$ releasing hormone $(G H R H)$ have been documented in some patients with X-LAG implying that hypothalamic GHRH dysregulation may be involved in the pathophysiology of the disease [76]. When overexpressed GPR101 is constitutively activated even in the absence of ligand and leads to increased cAMP levels [72].

Germline duplications of Xq26.3 mainly emerge sporadically and affect predominantly females. Familial presentation has been documented in three kindreds to date with the transmission of the genetic abnormality from mother to son with $100 \%$ penetrance [77]. In cases of sporadic males, somatic mosaicism is present [78]. $\mathrm{X}$-LAG is characterized by extreme acceleration of linear growth in very young infants who are usually normal-sized at birth. The very early age at disease onset means these patients have longer period of overgrowth if untreated and may reach very extreme final heights. Patients experience symptoms of adult acromegaly like soft tissue swelling and enlargement of hands and feet as well as coarse facial features and increased interdental diastemata. Additionally, a quarter of them have increased appetite, while insulin resistance and acanthosis nigricans may also be present [73]. Pituitary tumors in X-LAG are large for the age of the patients and can arise against the background of pituitary hyperplasia. GH levels can be extremely elevated and hyperprolactinemia is almost always present. Management of GH excess in patients with X-LAG can be particularly difficult due to large tumor size and young patient age. To control GH hypersecretion, radical surgery is needed and often is accompanied by hypopituitarism. Almost all patients with X-LAG are resistant to somatostatin analogues. Pegvisomant can be effective in controlling IGF-1 levels and limiting linear growth [73].

\section{P Association}

The coexistence of pheochromocytoma and paragangliomas (PPGL) and pituitary adenoma has been reported quite rarely since the 1950s. In 2012 a pathogenic mutation in SDHD - one of the many genes predisposing to PPGL - was reported in a patient with somatotroph adenoma and bilateral pheochromocytomas [79]. This led to the definition of a new condition including pituitary adenomas and PPGL that was termed the " 3 P association" (3PAs) [80]. The condition is extremely rare with less than 100 patients reported in literature and even fewer in whom genetic alterations have been identified. The majority are germline loss-of-function mutations that affect the genes coding the subunits of succinate dehydrogenase (SDH) complex - SDHD, SDHB, SDHC, SDHA, and succinate dehydrogenase complex assembly factor 2 (SDHAF2) [81]. $\mathrm{SDH}$-related tumorigenesis has been studied in detail in familial and sporadic PPGL. The SDH complex plays a crucial role in both Krebs cycle and electron transport chain in mitochondria. It consists of four subunits - hydrophilic A and B subunits which constitute the catalytic part of the enzyme and convert succinate to fumarate, and hydrophobic $C$ and $D$ subunits responsible for docking the complex to the inner mitochondrial membrane and providing electrons to the ubiquinone pool [82]. Inactivating mutations in any subunit genes impair the function of the enzyme and lead to succinate accumulation. This in turn is followed by inhibition of pro- 
lylhydroxylases (PHD) which are responsible for inactivation of hypoxia-inducible factor 1 alpha (HIF-1A). This protein acts as transcription factor and its accumulation causes a state of tissue pseudohypoxia and induces expression of HIF-responsive genes like VEGF which have been demonstrated to be involved in tumor development [83]. Disruption of the electron transport chain leads to generation of reactive oxygen species which additionally inhibit PHDs and stabilize HIF-1A. Succinate also inhibits histone demethylases and its accumulation in $\mathrm{SDH}$-deficient tissues results in genomic hypermethylation which has been shown in $\mathrm{SDH}$-mutant paragangliomas [84]. The prevalence of $S D H$ mutations in unselected pituitary adenomas and in patients with sporadic 3PAs is low. In cases with family history of PPGL, however, mutations can be identified in up to $75 \%$ of 3PAs patients [80]. In the overall cohort of 3PAs, somatotropinomas may be the most common phenotype, followed by prolactinomas, NFPA and corticotropinomas while macroadenomas prevail over microadenomas [85]. In the group of patients with SDH mutations, however, prolactinomas were more frequently present as compared to somatotropinomas and NFPA. These pituitary tumors can exhibit aggressive behavior, often requiring surgery and may be resistant to medical treatment [80]. A non-functioning pituitary carcinoma with mutation in $S D H B$ has also been reported [86]. A specific feature of SDH-mutated pituitary tumors is the presence of intracytoplasmic vacuoles [87]. Apart from derangements of the SDH complex, 3PAs can be expanded to other known PPGL genes. Alterations of MAX gene on chromosome 14q23.3 including intragenic deletions have recently been reported in patients with pheochromocytoma and pituitary tumors - prolactinomas and somatotropinomas [88]. Several cases of PA in patients with genetically confirmed von Hippel-Lindau (VHL) and MEN 2 syndromes have been described, however, in none of these cases was a causative mutation of VHL or RET definitively linked to pituitary tumorigenesis [82].

\section{Neurofibromatosis Type 1}

Neurofibromatosis type 1 (NF1) is an autosomal dominant cancer syndrome caused by germline inactivating mutations in NF1 gene on chromosome 17q11.2. The genetic product, neurofibromin, participates in the control of cell growth and proliferation by inhibiting Ras activity and regulating cAMP levels [89]. NF1 is characterized by café-au-lait skin spots, intertriginous freckling, Lisch nodules, neurofibromas, bone lesions and optic pathway gliomas. Acromegaly and gigantism have been described in patients with NF1 but pituitary tumors have been reported in very few [82, 90]. It has been suggested that compression from optic gliomas may prevent somatostatin mediated inhibition and lead to $\mathrm{GH}$ excess [90]. A causative role for NF1 mutations was not confirmed in any pituitary adenoma that occurred in NF1 patients. No associations of pheochromocytoma and PA in the setting of NF1 have been described so far.

\section{DICER1 Syndrome}

DICER1 is an autosomal dominant familial tumor/dysplasia disorder with low penetrance caused by inactivating mutations in DICER1 gene located on chromosome $14 q 32.13$. It is characterized by a number of benign and malignant tumors, most frequently pleuropulmonary blastoma and ovarian sex cord stromal tumors and less often cystic nephroma, Wilms tumor, renal sarcoma, multinodular

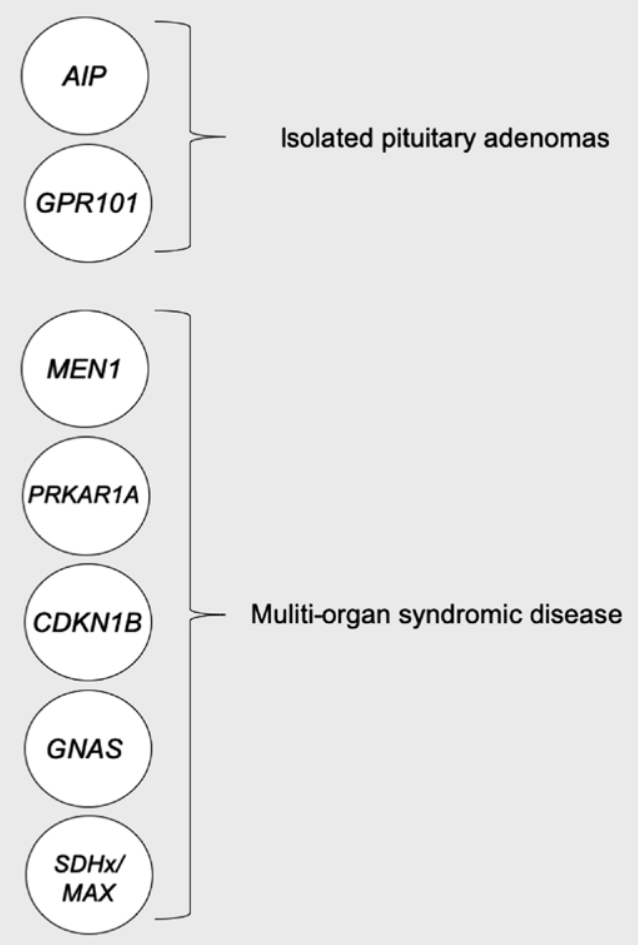

AIP: FIPA, pituitary gigantism, pediatric pituitary adenomas

GPR101: X-LAG, rare FIPA kindreds

MEN1 (MEN1 syndrome): Occasionally pediatric onset All clinical pituitary adenoma subtypes seen

PRKAR1A (Carney complex) Acromegaly predominantly

CDKN1B (MEN4)

Various clinical clinical pituitary

adenoma subtypes seen

GNAS (McCune Albright Syndrome)

Acromegaly and gigantism

Somatic mutations in acromegaly

SDHX/MAX (3P Association)

Acromegaly, prolactinoma

- Fig. 1 Principal causes of pituitary adenomas associated with germline and mosaic genetic mutations. 
goiter, differentiated thyroid carcinoma, nasal chondromesenchymal hamartoma, ciliary body medulloepithelioma, genitourinary embryonal rhabdomyosarcoma, and pinealoblastoma [91]. Among others, pituitary blastoma has also been described as a rare presentation of DICER 1 syndrome in 14 patients to date [81, 92]. The risk for tumor formation is highest in early childhood and decreases with age. DICER 1 codes for the 1922 amino acid cytoplasmic endoribonuclease class III (RNase-III) which is engaged in the genesis of microRNAs (miRNA). These miRNAs participate in gene silencing and block the translation of mRNA, thus inhibiting gene expression and regulating protein synthesis [93]. A prerequisite for tumor formation is the presence of loss-of-function mutations and a second tumor-specific mutation at several hotspots. Most affected children harbor inherited germline mutations but around $20 \%$ may arise de novo. Mosaicism has been detected in approximately $10 \%$ of patients with DICER1 syndrome and may be associated with earlier onset of disease and multiple affected sites [91]. Pituitary blastoma in DICER1 syndrome presents with severe ACTH-dependent Cushing's disease in infancy or early childhood and is fatal in nearly half of the affected patients [92]. The term blastoma is used for this pituitary tumors because on histology they resemble fetal pituitary tissue at 10-12 week gestation with only ACTH and GH secreting cells present among primitive Rathke-like epithelium [94].

\section{Tuberous Sclerosis Complex}

Tuberous sclerosis complex (TSC) is an autosomal dominant phakomatosis that presents with multiple hamartomas of brain, skin, heart, lungs, and kidneys. Brain involvement results in seizures, autism and cognitive disability. The disease is caused by loss-of-function mutations in either the TSC1 gene on chromosome 9q34.13 or the TSC2 gene on chromosome 16p13.3. Their products, hamartin and tuberin respectively, take part in the formation of TSC complex which act as negative regulator of mammalian target of rapamycin complex 1 (mTORC1). Disruption of TSC complex leads to activation of mTORC1 signaling with increased cell proliferation [95]. Pituitary adenomas are not a usual presentation of TSC but two cases of corticotropinomas have been described [96, 97].

\section{Conclusion}

Recent progress in molecular genetics has led to the identification of a number of novel genetic causes for pituitary adenomas. These include germline mutations predisposing to syndromic or isolated presentation ( $>$ Fig. 1 ) as well as somatic and mosaic genetic alterations. Screening for genetic defects in familial cases may identify at-risk individuals among affected families and lead to preclinical diagnosis. Better understanding of the molecular pathophysiology of pituitary tumors may provide basis for the future development of specifically targeted therapeutic tools and translate in better prevention and appropriate management of individual patients.

\section{Funding}

This work was supported by grants from the JABBS Foundation, UK and the Fonds d'Investissement Pour la Recherche Scientifique (FIRS), CHU de Liège, Belgium

\section{Conflict of Interest}

The authors declare that they have no conflict of interest.

\section{References}

[1] Ostrom QT, Gittleman H, Truitt G et al. CBTRUS Statistical Report: Primary brain and other central nervous system tumors diagnosed in the United States in 2011-2015. Neuro Oncol 2018; 20: iv1-iv86

[2] Ezzat S, Asa SL, Couldwell WT et al. The prevalence of pituitary adenomas: a systematic review. Cancer 2004; 101: 613-619

[3] Daly AF, Rixhon M, Adam C et al. High prevalence of pituitary adenomas: A cross-sectional study in the province of Liege, Belgium. J Clin Endocrinol Metab 2006; 91: 4769-4775

[4] Fontana E, Gaillard R. Epidemiology of pituitary adenoma: Results of the first Swiss study. Rev Med Suisse 2009; 5: 2172-2174

[5] Fernandez A, Karavitaki N, Wass JA. Prevalence of pituitary adenomas: A community-based, cross-sectional study in Banbury (Oxfordshire, UK). Clin Endocrinol (Oxf) 2010; 72: 377-382

[6] Gruppetta M, Mercieca C, Vassallo J. Prevalence and incidence of pituitary adenomas: A population based study in Malta. Pituitary 2013; 16: 545-553

[7] Herman V, Fagin J, Gonsky R et al. Clonal origin of pituitary adenomas. J Clin Endocrinol Metab 1990; 71: 1427-1433

[8] Daly AF, Tichomirowa MA, Beckers A. The epidemiology and genetics of pituitary adenomas. Best Pract Res Clin Endocrinol Metab 2009; 23: 543-554

[9] Landis CA, Masters SB, Spada A et al. GTPase inhibiting mutations activate the alpha chain of $G$ s and stimulate adenylyl cyclase in human pituitary tumours. Nature 1989; 340: 692-696

[10] Xekouki P, Azevedo M, Stratakis CA. Anterior pituitary adenomas: Inherited syndromes, novel genes and molecular pathways. Expert Rev Endocrinol Metab 2010; 5: 697-709

[11] Taboada GF, Tabet AL, Naves LA et al. Prevalence of gsp oncogene in somatotropinomas and clinically non-functioning pituitary adenomas: Our experience. Pituitary 2009; 12: 165-169

[12] Riminucci M, Collins MT, Lala R et al. An R201H activating mutation of the GNAS1 (Gsalpha) gene in a corticotroph pituitary adenoma. Mol Pathol 2002; 55: 58-60

[13] Spada A, Arosio M, Bochicchio D et al. Clinical, biochemical, and morphological correlates in patients bearing growth hormone-secreting pituitary tumors with or without constitutively active adenylyl cyclase. J Clin Endocrinol Metab 1990; 71: 1421-1426

[14] Picard C, Silvy M, Gerard C et al. Gs alpha overexpression and loss of Gs alpha imprinting in human somatotroph adenomas: Association with tumor size and response to pharmacologic treatment. Int J Cancer 2007; 121: 1245-1252

[15] McCune D]. Osteita fibrosa cystica : the case of nine-year-old girl who also exhibits precocious puberty, multiple pigmentation of the skin and hyperthyroidism. Am J Dis. Children 1936; 52: 743-744

[16] Vasilev V, Daly AF, Thiry A et al. McCune-Albright syndrome: A detailed pathological and genetic analysis of disease effects in an adult patient. J Clin Endocrinol Metab 2014; 99: E2029-E2038

[17] Collins MT, Singer FR, Eugster E. McCune-Albright syndrome and the extraskeletal manifestations of fibrous dysplasia. Orphanet J Rare Dis 2012; 7: (Suppl 1): S4

[18] Mantovani G, Bondioni S, Lania AG et al. Parental origin of Gsalpha mutations in the McCune-Albright syndrome and in isolated endocrine tumors. J Clin Endocrinol Metab 2004; 89: 3007-3009 
[19] Ruggieri P, Sim FH, Bond JR et al. Malignancies in fibrous dysplasia. Cancer 1994; 73: 1411-1424

[20] VolkI TM, Dorr HG. McCune-Albright syndrome: Clinical picture and natural history in children and adolescents. J Pediatr Endocrinol Metab 2006; 19: (Suppl 2) 551-559

[21] Akintoye SO, Kelly MH, Brillante B et al. Pegvisomant for the treatment of gsp-mediated growth hormone excess in patients with McCune-Albright syndrome. J Clin Endocrinol Metab 2006; 91: 2960-2966

[22] Reincke M, Sbiera S, Hayakawa A et al. Mutations in the deubiquitinase gene USP8 cause Cushing's disease. Nat Genet 2015; 47: 31-38

[23] Reyes-Turcu FE, Ventii KH, Wilkinson KD. Regulation and cellular roles of ubiquitin-specific deubiquitinating enzymes. Annu Rev Biochem 2009; 78: 363-397

[24] Meijer IM, Kerperien J, Sotoca AM et al. The Usp8 deubiquitination enzyme is post-translationally modified by tyrosine and serine phosphorylation. Cell Signal 2013; 25: 919-930

[25] Faucz FR, Tirosh A, Tatsi C et al. Somatic USP8 gene mutations are a common cause of pediatric cushing disease. J Clin Endocrinol Metab 2017; 102: 2836-2843

[26] Albani A, Theodoropoulou M, Reincke M. Genetics of Cushing's disease. Clin Endocrinol (Oxf) 2018; 88: 3-12

[27] Hayashi K, Inoshita N, Kawaguchi K et al. The USP8 mutational status may predict drug susceptibility in corticotroph adenomas of Cushing's disease. Eur J Endocrinol 2016; 174: 213-226

[28] Cohen M, Persky R, Stegemann R et al. Germline USP8 mutation associated with pediatric Cushing disease and other clinical features: A new syndrome. J Clin Endocrinol Metab 2019; 104: 4676-4682

[29] Hernandez-Ramirez LC, Gam R, Valdes N et al. Loss-of-function mutations in the CABLES1 gene are a novel cause of Cushing's disease. Endocr Relat Cancer 2017; 24: 379-392

[30] Roussel-Gervais A, Couture C, Langlais D et al. The Cables1 gene in glucocorticoid regulation of pituitary corticotrope growth and cushing disease. J Clin Endocrinol Metab 2016; 101: 513-522

[31] Thakker RV. Multiple endocrine neoplasia type 1 (MEN1) and type 4 (MEN4). Mol Cell Endocrinol 2014; 386: 2-15

[32] Larsson C, Skogseid B, Oberg K et al. Multiple endocrine neoplasia type 1 gene maps to chromosome 11 and is lost in insulinoma. Nature 1988; 332: 85-87

[33] Chandrasekharappa SC, Guru SC, Manickam P et al. Positional cloning of the gene for multiple endocrine neoplasia-type 1. Science 1997; 276: 404-407

[34] Lemos MC, Thakker RV. Multiple endocrine neoplasia type 1 (MEN1): Analysis of 1336 mutations reported in the first decade following identification of the gene. Hum Mutat 2008; 29: 22-32

[35] Falchetti A. Genetics of multiple endocrine neoplasia type 1 syndrome: What's new and what's old. [version 1; peer review: 3 approved]. F1000 Research 2017, 6 (F1000 Faculty Rev): 73

[36] Falchetti A, Marini F, Luzi E et al. Multiple endocrine neoplasms. Best Pract Res Clin Rheumatol 2008; 22: 149-163

[37] Marini F, Falchetti A, Del Monte F et al. Multiple endocrine neoplasia type 1. Orphanet J Rare Dis 2006; 1: 38

[38] Syro LV, Scheithauer BW, Kovacs K et al. Pituitary tumors in patients with MEN1 syndrome. Clinics (Sao Paulo) 2012; 67: (Suppl 1) 43-48

[39] Scheithauer BW, Laws ER Jr., Kovacs K et al. Pituitary adenomas of the multiple endocrine neoplasia type I syndrome. Semin Diagn Pathol 1987; 4: 205-211

[40] Verges B, Boureille F, Goudet P et al. Pituitary disease in MEN type 1 (MEN1): Data from the France-Belgium MEN1 multicenter study. J Clin Endocrinol Metab 2002; 87: 457-465

[41] Kamilaris CDC, Faucz FR, Voutetakis A et al. Carney Complex. Exp Clin Endocrinol Diabetes 2019; 127: 156-164
[42] Kirschner LS, Carney JA, Pack SD et al. Mutations of the gene encoding the protein kinase $A$ type I-alpha regulatory subunit in patients with the Carney complex. Nat Genet 2000; 26: 89-92

[43] Robinson-White A, Meoli E, Stergiopoulos S et al. PRKAR1A Mutations and protein kinase $A$ interactions with other signaling pathways in the adrenal cortex. J Clin Endocrinol Metab 2006; 91: 2380-2388

[44] Stratakis CA, Carney JA, Lin JP et al. Carney complex, a familial multiple neoplasia and lentiginosis syndrome. Analysis of 11 kindreds and linkage to the short arm of chromosome 2. J Clin Invest 1996; 97: 699-705

[45] Forlino A, Vetro A, Garavelli L et al. PRKACB and Carney complex. N Engl J Med 2014; 370: 1065-1067

[46] Boikos SA, Stratakis CA. Carney complex: The first 20 years. Curr Opin Oncol 2007; 19: 24-29

[47] Kirschner LS. PRKAR1A and the evolution of pituitary tumors. Mol Cell Endocrinol 2010; 326: 3-7

[48] Pepe S, Korbonits M, lacovazzo D. Germline and mosaic mutations causing pituitary tumours: Genetic and molecular aspects. J Endocrinol 2019; 240: R21-R45

[49] Bertherat J, Horvath A, Groussin L et al. Mutations in regulatory subunit type $1 \mathrm{~A}$ of cyclic adenosine 5 '-monophosphate-dependent protein kinase (PRKAR1A): Phenotype analysis in 353 patients and 80 different genotypes. J Clin Endocrinol Metab 2009; 94: 2085-2091

[50] Pellegata NS, Quintanilla-Martinez L, Siggelkow H et al. Germ-line mutations in p27Kip1 cause a multiple endocrine neoplasia syndrome in rats and humans. Proc Natl Acad Sci USA 2006; 103: 15558-15563

[51] Alrezk R, Hannah-Shmouni F, Stratakis CA. MEN4 and CDKN1B mutations: The latest of the MEN syndromes. Endocr Relat Cancer 2017; 24: T195-T208

[52] Frederiksen A, Rossing M, Hermann P et al. Clinical Features of Multiple Endocrine Neoplasia Type 4 - Novel pathogenic variant and review of published cases. J Clin Endocrinol Metab 2019; 104: 3637-3646

[53] Lee M, Pellegata NS. Multiple endocrine neoplasia type 4. Front Horm Res 2013; 41: 63-78

[54] Agarwal SK, Mateo CM, Marx SJ. Rare germline mutations in cyclin-dependent kinase inhibitor genes in multiple endocrine neoplasia type 1 and related states. J Clin Endocrinol Metab 2009; 94: 1826-1834

[55] Daly AF, Jaffrain-Rea ML, Ciccarelli A et al. Clinical characterization of familial isolated pituitary adenomas. J Clin Endocrinol Metab 2006; 91: 3316-3323

[56] Beckers A, Daly AF. The clinical, pathological, and genetic features of familial isolated pituitary adenomas. Eur J Endocrinol 2007; 157: 371-382

[57] Beckers A, Aaltonen LA, Daly AF et al. Familial isolated pituitary adenomas (FIPA) and the pituitary adenoma predisposition due to mutations in the aryl hydrocarbon receptor interacting protein (AIP) gene. Endocr Rev 2013; 34: 239-277

[58] Marques NV, Kasuki L, Coelho MC et al. Frequency of familial pituitary adenoma syndromes among patients with functioning pituitary adenomas in a reference outpatient clinic. J Endocrinol Invest 2017; 40: $1381-1387$

[59] Vierimaa O, Georgitsi M, Lehtonen R et al. Pituitary adenoma predisposition caused by germline mutations in the AIP gene. Science 2006; 312: 1228-1230

[60] Daly AF, Tichomirowa MA, Petrossians P et al. Clinical characteristics and therapeutic responses in patients with germ-line AIP mutations and pituitary adenomas: An International Collaborative Study. J Clin Endocrinol Metab 2010; 95: E373-E383 
[61] Hernandez-Ramirez LC, Gabrovska P, Denes J et al. Landscape of familial isolated and young-onset pituitary adenomas: Prospective diagnosis in AIP mutation carriers. J Clin Endocrinol Metab 2015; 100: E1242-E1254

[62] Lecoq AL, Kamenicky P, Guiochon-Mantel A et al. Genetic mutations in sporadic pituitary adenomas-what to screen for? Nat Rev Endocrinol 2015; 11: 43-54

[63] Beckers A, Petrossians P, Hanson J, Daly AF. The causes and consequences of pituitary gigantism. Nat Rev Endocrinol 2018; 14: 705-720

[64] Ozfirat Z, Korbonits M. AIP gene and familial isolated pituitary adenomas. Mol Cell Endocrinol 2010; 326: 71-79

[65] Formosa R, Borg J, Vassallo J. Aryl hydrocarbon receptor (AHR) is a potential tumour suppressor in pituitary adenomas. Endocr Relat Cancer 2017; 24: 445-457

[66] Kazlauskas A, Poellinger L, Pongratz I. The immunophilin-like protein XAP2 regulates ubiquitination and subcellular localization of the dioxin receptor. J Biol Chem 2000; 275: 41317-41324

[67] Tuominen I, Heliovaara E, Raitila A et al. AIP inactivation leads to pituitary tumorigenesis through defective Galphai-cAMP signaling. Oncogene 2015; 34: 1174-1184

[68] Hernandez-Ramirez LC, Trivellin G, Stratakis CA. Role of Phosphodiesterases on the Function of Aryl Hydrocarbon Receptor-Interacting Protein (AIP) in the Pituitary Gland and on the Evaluation of AIP Gene Variants. Horm Metab Res 2017; 49: 286-295

[69] Schernthaner-Reiter MH, Trivellin G, Stratakis CA. Interaction of AIP with protein kinase A (cAMP-dependent protein kinase). Hum Mol Genet 2018; 27: 2604-2613

[70] Hernandez-Ramirez LC, Morgan RML, Barry S et al. Multi-chaperone function modulation and association with cytoskeletal proteins are key features of the function of AIP in the pituitary gland. Oncotarget 2018; 9: 9177-9198

[71] Rostomyan L, Potorac I, Beckers P et al. AIP mutations and gigantism. Ann Endocrinol (Paris) 2017; 78: 123-130

[72] Trivellin G, Daly AF, Faucz FR et al. Gigantism and acromegaly due to Xq26 microduplications and GPR101 mutation. N Engl J Med 2014; 371: 2363-2374

[73] Beckers A, Lodish MB, Trivellin G et al. X-linked acrogigantism syndrome: Clinical profile and therapeutic responses. Endocr Relat Cancer 2015; 22: 353-367

[74] lacovazzo D, Caswell R, Bunce B et al. Germline or somatic GPR101 duplication leads to X-linked acrogigantism: a clinico-pathological and genetic study. Acta Neuropathol Commun 2016; 4: 56

[75] Trivellin G, Bjelobaba I, Daly AF et al. Characterization of GPR101 transcript structure and expression patterns. J Mol Endocrinol 2016; 57: $97-111$

[76] Daly AF, Lysy PA, Desfilles C et al. GHRH excess and blockade in X-LAC syndrome. Endocr Relat Cancer 2016; 23: 161-170

[77] Beckers A, Rostomyan L, Potorac I et al. X-LAG: How did they grow so tall? Ann Endocrinol (Paris) 2017; 78: 131-136

[78] Daly AF, Yuan B, Fina F et al. Somatic mosaicism underlies X-linked acrogigantism syndrome in sporadic male subjects. Endocr Relat Cancer 2016; 23: 221-233
[79] Xekouki P, Pacak K, Almeida M et al. Succinate dehydrogenase (SDH) D subunit (SDHD) inactivation in a growth-hormone-producing pituitary tumor: A new association for SDH? J Clin Endocrinol Metab 2012; 97: E357-E366

[80] Xekouki P, Szarek E, Bullova P et al. Pituitary adenoma with paraganglioma/pheochromocytoma (3PAs) and succinate dehydrogenase defects in humans and mice. J Clin Endocrinol Metab 2015; 100: E710-E719

[81] Hernandez-Ramirez LC, Stratakis CA. Genetics of Cushing's Syndrome. Endocrinol Metab Clin North Am 2018; 47: 275-297

[82] O'Toole SM, Denes ], Robledo M et al. 15 Years of Paraganglioma: The association of pituitary adenomas and phaeochromocytomas or paragangliomas. Endocr Relat Cancer 2015; 22: T105-T122

[83] Selak MA, Armour SM, MacKenzie ED et al. Succinate links TCA cycle dysfunction to oncogenesis by inhibiting HIF-alpha prolyl hydroxylase. Cancer Cell 2005; 7: 77-85

[84] Letouze E, Martinelli C, Loriot C et al. SDH mutations establish a hypermethylator phenotype in paraganglioma. Cancer Cell 2013; 23: 739-752

[85] Mannelli M, Canu L, Ercolino T et al. Diagnosis of Endocrine Disease: SDHx mutations: beyond pheochromocytomas and paragangliomas. Eur J Endocrinol 2018; 178: R11-R17

[86] Tufton N, Roncaroli F, Hadjidemetriou I et al. Pituitary carcinoma in a patient with an SDHB mutation. Endocr Pathol 2017; 28: 320-325

[87] Denes J, Swords F, Rattenberry E et al. Heterogeneous genetic background of the association of pheochromocytoma/paraganglioma and pituitary adenoma: Rresults from a large patient cohort. J Clin Endocrinol Metab 2015; 100: E531-E541

[88] Daly AF, Castermans E, Oudijk L et al. Pheochromocytomas and pituitary adenomas in three patients with MAX exon deletions. Endocr Relat Cancer 2018; 25: L37-L42

[89] Williams VC, Lucas ], Babcock MA et al. Neurofibromatosis type 1 revisited. Pediatrics 2009; 123: 124-133

[90] Hannah-Shmouni F, Trivellin G, Stratakis CA. Genetics of gigantism and acromegaly. Growth Horm IGF Res 2016; 30-31: 37-41

[91] Schultz KAP, Williams GM, Kamihara J et al. DICER1 and associated conditions: Identification of at-risk individuals and recommended surveillance strategies. Clin Cancer Res 2018; 24: 2251-2261

[92] de Kock L, Sabbaghian N, Plourde F et al. Pituitary blastoma: A pathognomonic feature of germ-line DICER1 mutations. Acta Neuropathol 2014; 128: 111-122

[93] Solarski M, Rotondo F, Foulkes WD et al. DICER1 gene mutations in endocrine tumors. Endocr Relat Cancer 2018; 25: R197-R208

[94] Scheithauer BW, Kovacs K, Horvath E et al. Pituitary blastoma. Acta Neuropathol 2008; 116: 657-666

[95] Lam HC, Nijmeh J, Henske EP. New developments in the genetics and pathogenesis of tumours in tuberous sclerosis complex. J Pathol 2017; 241: 219-225

[96] Tigas S, Carroll PV, Jones R et al. Simultaneous Cushing's disease and tuberous sclerosis; a potential role for TSC in pituitary ontogeny. Clin Endocrinol (Oxf) 2005; 63: 694-695

[97] Nandagopal R, Vortmeyer A, Oldfield EH et al. Cushing's syndrome due to a pituitary corticotropinoma in a child with tuberous sclerosis: An association or a coincidence? Clin Endocrinol (Oxf) 2007; 67: 639-641 